\title{
Update on the Treatment of Idiopathic Hypersomnia
}

\author{
M. S. Schinkelshoek ${ }^{1,2} \cdot$ R. Fronczek ${ }^{1,2} \cdot$ G. J. Lammers ${ }^{1,2}$
}

Published online: 25 November 2019

(C) The Author(s) 2019

\begin{abstract}
Purpose of Review Idiopathic hypersomnia is an incapacitating disorder with a profound impact on daytime performance and quality of life. The most commonly used treatment modalities are lifestyle advice and pharmacological therapy. We present an update on the evidence concerning treatment options for idiopathic hypersomnia.

Recent Findings Evidence for non-pharmacological interventions is lacking; improvement in symptoms on introducing these interventions is often less pronounced than in narcolepsy. Additional pharmacological treatment is therefore usually initiated. The few treatment studies that have been performed are hampered by small sample sizes and the use of variable and often insufficiently validated outcome parameters for the whole spectrum of idiopathic hypersomnia symptoms.

Conclusion Evidence on treatment is scarce. Since the efficacy of modafinil is consistently described and there is much experience with this substance, it is reasonable to start with modafinil as a first choice treatment. Methylphenidate and dexamphetamine are good alternatives. In the future, newer drugs such as sodium oxybate, pitolisant, and solriamfetol might be authorized for use in idiopathic hypersomnia.
\end{abstract}

Keywords Idiopathic hypersomnia $\cdot$ Treatment $\cdot$ Medication $\cdot$ Hypersomnolence $\cdot$ Excessive daytime sleepiness

\section{Introduction}

The diagnostic criteria for idiopathic hypersomnia (IH), as defined in the three editions of the International Classification of Sleep Disorders (ICSD) published between 1979 and 2014, have changed considerably over the years. This has unintentionally led to much confusion about this rare and poorly understood disorder. It may also have prevented us gaining knowledge about the pathophysiology and the best treatment options.

This article is part of the Topical Collection on Hypersomnia Disorders

G. J. Lammers

G.J.Lammers@1umc.nl

M. S. Schinkelshoek

M.S.Schinkelshoek@lumc.nl

R. Fronczek

R.Fronczek@lumc.nl

1 Department of Neurology, Leiden University Medical Center, Albinusdreef 2, 2333ZA, Leiden, The Netherlands

2 Sleep-Wake Centre, Stichting Epilepsie Instellingen Nederland (SEIN), Heemstede, The Netherlands
In the early years, the "classical type" of IH was defined as increased need for sleep over the $24 \mathrm{~h}$ of the day, with prolonged duration of nighttime sleep. Later, another phenotype was added that was better characterized by an inability to stay awake during the waking part of the day than by an increased amount of sleep. In the current classification, they are described together. This seems to have happened because there is no evidence that the various phenotypes have different underlying pathophysiologies. However, neither is there evidence that they share a common pathophysiology. It seems probable that multiple pathophysiological pathways may result in each of the phenotypes. Unfortunately, there is an additional problem with the phenotype characterized by an inability to stay awake; there are no generally accepted criteria to separate this from chronic sleep deprivation, and in recent years, it has become clear that the delineation from narcolepsy type 2 (NT2) is problematic.

In this review, we use the criteria of the third and current edition of the classification, the ICSD-3 [1]. The criteria for diagnosing $\mathrm{IH}$ are as shown in Table 1.

Where relevant, we will describe the efficacy of treatment for both phenotypes separately.

$\mathrm{IH}$ is an incapacitating disorder with profound impact on daytime performance and quality of life. Those with the type with prolonged nighttime sleep additionally have difficulty 
Table 1 ICSD-3 criteria idiopathic hypersomnia (IH) [1]

Criteria for the diagnosis of IH according to the International Classification of Sleep Disorders - 3rd edition:

1. The patient has daily periods of irrepressible need to sleep or daytime lapses into sleep occurring for at least 3 months.

2. Cataplexy is absent.

3. A multiple sleep latency test (MSLT) performed according to standard techniques shows fewer than two sleep onset REM periods or no sleep onset REM periods if the REM latency on the preceding polysomnogram was $\leq 15 \mathrm{~min}$.

4. The presence of at least one of the following:

- The MSLT shows a mean sleep latency of $\leq 8 \mathrm{~min}$;

- Total $24-\mathrm{h}$ sleep time is $\geq 660$ min (typically $12-14 \mathrm{~h}$ ) on $24-\mathrm{h}$ polysomnographic monitoring (performed after correction of chronic sleep deprivation), or by wrist actigraphy in association with a sleep $\log$ (averaged over at least 7 days with unrestricted sleep).

5. Insufficient sleep syndrome is ruled out (if deemed necessary, by lack of improvement of sleepiness after an adequate trial of increased nocturnal time in bed, preferably confirmed by at least a week of wrist actigraphy);

6. The hypersomnolence and/or MSLT findings are not better explained by another sleep disorder, other medical or psychiatric disorder or use of drugs or medications.

rising in the morning making it difficult to fit in educational programs or to work starting (early) in the morning [2]. A start in (early) childhood is even more detrimental, since it has additional negative impact on social development and achievements at school.

Lifestyle advice and pharmacological therapy are the two treatment modalities most commonly used for the treatment of IH. Our update is limited to these options, and to some still unproven or insufficiently validated new approaches.

\section{Recent Findings}

We performed a systematic review of the literature on the treatment of IH. Clinical-trial.gov database, Medline, PubMed, and Web of Science were interrogated using the keywords in different combinations ('hypersomnolence, idiopathic'[MeSH Terms] OR ('hypersomnolence'[All Fields] AND 'idiopathic'[All Fields]) OR 'idiopathic hypersomnolence'[All Fields] OR ('idiopathic'[All Fields] AND 'hypersomnia'[All Fields]) OR 'idiopathic hypersomnia'[All Fields] AND ('therapy'[Subheading] OR 'therapy'[All Fields] OR 'treatment'[MeSH Terms] OR 'therapeutics'[All Fields]. References of reviews and original articles that this search yielded were assessed for publications on treatment of IH that were missed during the original search.

Published research on IH is scarce and, in the published studies, sample sizes are mostly small, due to a low prevalence. This leads to combination trials in both narcolepsy and $\mathrm{IH}$ and to the absence of drugs to treat $\mathrm{IH}$ that are approved by the European Medicine Agency (EMA).
Almost all studies are open label studies, and as already mentioned, the interpretation is difficult because of the changing definitions of the disorder over time. This leads to large heterogeneity in the published case series and clinical trials. In addition, inclusion and exclusion criteria vary, focusing mostly on individuals with either treatment-naïve or treatmentrefractory $\mathrm{IH}$.

The third important problem is the lack of outcome parameters that effectively reflect the burden of IH. This explains the large variety of outcome parameters that have been used in pharmacological studies. The most frequently used parameters are copied from narcolepsy research: the multiple sleep latency test (MSLT), and the maintenance of wakefulness test (MWT) for objective assessment of daytime sleepiness. However, MSLT test-retest reliability is low in IH $[3 \cdot, 4 \cdot \bullet]$. Moreover, a validation of the MSLT's ability to monitor changes in objective daytime sleepiness is lacking. Tools for subjective measurement of excessive daytime sleepiness (EDS) are the Epworth Sleepiness Scale (ESS), which reflects perceived daytime sleepiness, and the recently published Idiopathic Hypersomnia Severity Scale [5••]. This last scale is the first to assess IH in a broader context than just the sleepiness symptoms. It includes, for example, a score for daytime performance and sleep inertia. So far, it has only been validated in a cohort of people with IH with long sleep time. Other parameters used are vigilance tasks $[6,7]$ and driving (simulations) [8]. Thus far, however, no outcome parameter has proved to be an adequate reflection of, or a monitoring tool for, disease severity.

\section{Non-pharmacological Treatment}

In clinical practice, non-pharmacological interventions are the cornerstones of treatment of narcolepsy and IH [9-11]. After the diagnosis has been established, the first step is to inform the individual about the disease and its prognosis, as well as to explain the current knowledge of the condition. Additionally, counseling for school- or work-related issues, psychosocial guidance and medical follow-up to assess disease progression and treatment efficacy is warranted [12,13]. Further strategies include self-care and behavioral therapy, in which advice on short daytime naps and scheduled regular nocturnal sleep times is provided. Additionally, psychotherapy and self-help groups, a balanced low-carbohydrate diet and physical activity are other options to be considered. However, evidence for these non-pharmacological interventions is lacking in IH and the improvement of symptoms on introducing these interventions is often less pronounced than in narcolepsy $[10,14]$.

The efficacy of cognitive behavioral therapy has not yet been described in $\mathrm{IH}$, but a clinical trial on the effect of cognitive behavioral therapy for hypersomnia (CBT-H) in 32 people with narcolepsy types 1 and 2 and $\mathrm{IH}$ is now being performed in which the patient-related health (PHQ) 
questionnaire is used as the primary outcome parameter (NCT03904238). Another ongoing trial is focusing on the effect of sleep restriction on endogenous melatonin, vigilance and cognition in people with IH with long sleep time (NCT03356938).

A new and different non-pharmacological approach was described in a cohort of 8 people with $\mathrm{IH}$ in which transcranial direct current stimulation significantly improved subjective daytime sleepiness (ESS) and attention [15]. A current trial examining this approach is also in progress (NCT03198156).

\section{Pharmacological Treatment}

Most people with IH do not experience sufficient improvement with non-pharmacological interventions alone, so additional pharmacological treatment is usually initiated. Unfortunately, no compound has marketing authorization for the treatment of IH. Only pentetrazole has orphan designation by the European Medicines Agency (EMA). An overview of studies on pharmacological treatment can be found in Table 2 .

\section{Modafinil}

The best-studied compound for the treatment of IH is modafinil. Modafinil increases the extracellular dopamine concentration by blocking the dopamine transporter. Until 2011, modafinil was the only drug that had marketing authorization in some countries for the treatment of IH. The EMA withdrew its indication, however, because the severity of the disorder was considered not to outweigh side effects including the risk of skin or hypersensitivity reactions and neuropsychiatric disorders; this opinion was not generally shared by experts. Since then, two randomized controlled trials have increased the body of evidence suggesting that modafinil has comparable efficacy in people with IH without long sleep as it has in narcolepsy patients. This information adds to earlier case series and small-scale clinical trials that have been performed in the past few decades [7, 17-21, 34]. The first crossover double-blind randomized controlled trial was assessing real driving performance and excessive daytime sleepiness, objectified by MWT, in people with narcolepsy $(N=13)$ and IH $(N=14)$. Results were not presented separately for people with $\mathrm{IH}$, but real driving performance and excessive daytime sleepiness significantly improved during modafinil use in the patient group [8]. The second randomized controlled trial included 33 people with IH without long sleep to assess the effect of modafinil on excessive daytime sleepiness (ESS and MWT) and physician-reported improvement (Clinical Global Impression (CGI)) [16]. They reported a decrease in subjective daytime sleepiness (ESS) and improvement in CGI score, but no improvement of objective daytime sleepiness (MWT) in the modafinil group. Adverse effects were mild.
The effects of modafinil on excessive daytime sleepiness in $\mathrm{IH}$ as reported in the published studies seem comparable to narcolepsy, but the percentage of individuals who discontinue modafinil due to lack of efficacy of modafinil is reportedly high in people with IH with and without long sleep [19]. Interestingly, the addition of the connexin flecainide to modafinil was shown to improve the wake- and vigilancepromoting effects of modafinil in rodents $[35,36]$ and in healthy human subjects [37•]. The promising combination of these two compounds, called THN102, is now being investigated in a phase 2 trial in 51 people with narcolepsy (NCT02821715).

\section{Methylphenidate}

Methylphenidate is another stimulant that is frequently used in IH. It blocks particularly the reuptake of dopamine. No randomized clinical trials have been performed assessing the effect of this compound on IH symptoms, but several case series describe a benefit/risk ratio that is comparable to that of modafinil with $62-95 \%$ of responders to methylphenidate treatment with frequent, but mild adverse effects [19, 22, 23].

\section{Dextroamphetamine}

Information on the effect of dextroamphetamine in IH is scarce. It is mentioned in some case reports, with conflicting statements regarding efficacy, and responder rates ranging from 0 to $63 \%[18,19,22]$. The sparsity of data on the use of dextroamphetamine might be both because it is not available in many countries and also because of the disadvantageous adverse effect profile compared to other stimulants. There is one ongoing randomized controlled trial comparing modafinil and dextroamphetamine in 44 people with $\mathrm{IH}$ and narcolepsy type 2, assessing subjective daytime sleepiness. Patient-reported outcome parameters on sleepiness, sleep inertia and cognitive dysfunction are defined as secondary endpoints (NCT03772314).

\section{Sodium Oxybate}

Sodium oxybate, a compound with affinity for the GHB receptor but with therapeutic effect probably mediated through the GABA-B receptors, has been approved for the treatment of narcolepsy by both the EMA and the American Federal Drug Agency (FDA). Even though the promotion of sleep consolidation seems counterintuitive for the treatment of IH, a retrospective study on 46 people with treatment-refractory $\mathrm{IH}$ describes a good response in $65 \%$ of individuals, with benefit on severe sleep inertia in $71 \%$, on excessive daytime sleepiness in 55\% and shortened nighttime sleep time in 52\% [24•]. An ongoing randomized controlled phase $2 / 3$ trial in 48 people with $\mathrm{IH}$ assesses the effect of sodium oxybate on 
Table 2 Overview of medication studies in idiopathic hypersomnia $(\mathrm{IH})$, described in this review. The only randomized clinical trials are those by Philip et al. [8] and Mayer et al. [16] on modafinil and that by Trotti et al. [6] on clarithromycin. Since "improvement" and "responder/ response" in the last column were defined differently, or not at all, in most articles, this table does not contain all specific information on those definitions

\begin{tabular}{|c|c|c|c|c|}
\hline Treatment & Author & Dose & Patient population & Conclusion \\
\hline \multirow[t]{8}{*}{ Modafinil } & Bastuji et al., 1988 [17] & 200-500 mg per day & IH (confirmed by PSG; $n=15$ ) & $\begin{array}{l}\text { Decrease in episodes of } \\
\text { drowsiness } 60 \% \text {; in } \\
\text { sleep episodes } 80 \%\end{array}$ \\
\hline & $\begin{array}{l}\text { Anderson et al., } 2007 \\
{[18]}\end{array}$ & $100-1000 \mathrm{mg}$ per day & IH (ICSD-2; $n=54)$ & $62 \%$ responders \\
\hline & Ali et al., 2009 [19] & $367 \pm 141 \mathrm{mg}$ per day & IH (ICSD-2; $n=25)$ & $\begin{array}{l}95 \% \text { complete or } \\
\text { partial response }\end{array}$ \\
\hline & Lavault et al., 2011 [20] & $318 \pm 192 \mathrm{mg}$ per day & IH $($ ICSD- $2 / 3 ; n=104)$ & $\begin{array}{l}\text { Improvement on ESS: } \\
2.6 \text { points }\end{array}$ \\
\hline & $\begin{array}{l}\text { Janackova et al., } 2011 \\
\text { [21] }\end{array}$ & 200-400 mg per day & IH (ICSD- $2 ; n=2)$ & $100 \%$ responders \\
\hline & Philip et al., 2014 [8] & $400 \mathrm{mg}$ per day & $\begin{array}{l}\text { IH (ICSD-2; } \mathrm{n}=14) \\
\quad \text { narcolepsy (ICSD-2; } n=13 \text { ) }\end{array}$ & $\begin{array}{l}\text { Improvement SDLP } \\
\text { with } 1.3 \mathrm{~cm} \text {; decrease } \\
\text { ILC: } 1.0\end{array}$ \\
\hline & Mayer et al., 2015 [16] & $2 \times 100 \mathrm{mg}$ & $\begin{array}{l}\text { IH without long sleep } \\
\quad \text { time (ICSD-2; } n=31 \text { ) }\end{array}$ & $\begin{array}{l}\text { Improvement on ESS: } \\
6.0 \text { points; on CGI: } 1.0 \\
\text { point }\end{array}$ \\
\hline & Yaman et al., 2015 [7] & $200 \mathrm{mg}$ per day & $\mathrm{IH}(n=18)$ & $\begin{array}{l}\text { Improvement mean } \\
\text { P300 amplitudes }\end{array}$ \\
\hline \multirow[t]{3}{*}{ Methylphenidate } & Bassetti et al., 1997 [22] & Unclear & IH (ICSD- $1 ; n=28)$ & $\begin{array}{l}71 \% \text { responders (together } \\
\text { with } \\
\text { dextroamphetamine) }\end{array}$ \\
\hline & Ali et al., 2009 [19] & $51 \pm 27 \mathrm{mg}$ per day & IH (ICSD-2; $n=40)$ & $\begin{array}{l}95 \% \text { complete or partial } \\
\text { response }\end{array}$ \\
\hline & Thakrar et al., 2018 [23] & $19 \pm 10 \mathrm{mg}$ per day & $\begin{array}{l}\text { IH (ICSD-3; } n=9) ; \mathrm{NT} 1 \\
\quad(\mathrm{ICSD}-3 ; n=70), \mathrm{NT} 2 \\
\quad(\mathrm{ICSD}-3 ; n=47)\end{array}$ & $\begin{array}{l}\text { Improvement on ESS: } \\
3.1 \text { points }\end{array}$ \\
\hline \multirow[t]{3}{*}{ Dextroamphetamine } & Bassetti et al., 1997 [22] & Unclear & IH (ICSD-1; n = 28) & $\begin{array}{l}71 \% \text { responders (together } \\
\text { with methylphenidate) }\end{array}$ \\
\hline & $\begin{array}{l}\text { Anderson et al., } 2007 \\
{[18]}\end{array}$ & Unclear & IH (ICSD- $2 ; n=8)$ & $63 \%$ responders \\
\hline & Ali et al., 2009 [19] & $36 \pm 44 \mathrm{mg}$ per day & IH (ICSD-2; n = 2) & $\begin{array}{l}0 \% \text { complete or partial } \\
\text { response }\end{array}$ \\
\hline Sodium oxybate & $\begin{array}{l}\text { Leu-Semenescu et al., } \\
2016 \text { [24] }\end{array}$ & $4.3 \pm 2.2 \mathrm{~g}$ & $\begin{array}{l}\text { Treatment-refractory IH } \\
\quad \text { (ICSD- } 2 / 3 ; n=46)\end{array}$ & $\begin{array}{l}65 \% \text { responders; } \\
\text { improvement } \\
\text { on ESS: } 3.5 \text { points }\end{array}$ \\
\hline Pitolisant & $\begin{array}{l}\text { Leu-Semenescu et al., } \\
2014 \text { [25] }\end{array}$ & $5-50 \mathrm{mg}$ & $\begin{array}{l}\text { Treatment-refractory IH } \\
\quad(\mathrm{ICSD}-2 / 3 ; n=65)\end{array}$ & $\begin{array}{l}35 \% \text { responders; } \\
\text { improvement } \\
\text { on ESS: } 1.5 \text { points }\end{array}$ \\
\hline Mazindol & Nittur et al., 2013 [26] & $1-6 \mathrm{mg}$ & $\begin{array}{l}\text { Treatment-refractory IH } \\
\text { (ICSD-2/3; } n=37 \text { ) }\end{array}$ & $\begin{array}{l}\text { Improvement on ESS: } 4.8 \\
\text { points }\end{array}$ \\
\hline \multirow[t]{3}{*}{ Flumazenil } & Rye et al., 2012 [27] & $\begin{array}{l}0.35-2 \mathrm{mg} \\
\quad \text { (intravenous) }\end{array}$ & $\begin{array}{l}\text { Habitual long sleeper } \\
\qquad(\mathrm{n}=3), \text { narcolepsy } \\
\text { without cataplexy } \\
\text { (ICSD-2; } n=2), \mathrm{IH} \\
\text { (ICSD- } 2 ; n=2)\end{array}$ & $\begin{array}{l}\text { Improved psychomotor } \\
\text { vigilance and } \\
\text { subjective } \\
\text { alertness }\end{array}$ \\
\hline & Kelty et al., 2014 [28] & $\begin{array}{l}0.35-4 \mathrm{mg} / \text { day } \\
\quad \text { (subcutaneous) }\end{array}$ & $\mathrm{IH}(n=1)$ & $\begin{array}{l}\text { Improvement on ESS: } \\
10 \text { points }\end{array}$ \\
\hline & Trotti et al., 2016 [29] & 24-60 mg/day (oral) & $\begin{array}{l}\text { Refractory hypersomnolence } \\
\quad(n=153)\end{array}$ & $62.8 \%$ responders \\
\hline Clarithromycin & Trotti et al., 2014 [30] & $2 \times 500 \mathrm{mg}$ & $\begin{array}{l}\text { Primary hypersomnia } \\
\text { (DSM-IV; } n=41 \text { ), } \\
\text { narcolepsy without } \\
\text { cataplexy (DSM-IV; } n=12 \text { ) }\end{array}$ & $\begin{array}{r}64 \% \text { improvement in } \\
\text { daytime sleepiness }\end{array}$ \\
\hline
\end{tabular}


Table 2 (continued)

\begin{tabular}{|c|c|c|c|c|}
\hline Treatment & Author & Dose & Patient population & Conclusion \\
\hline & Trotti et al., 2015 [6] & & $\begin{array}{l}\text { IH (ICSD-2; } \mathrm{n}=10) ; \mathrm{NT} 2 \\
\quad \text { (ICSD- } 2 ; n=4) ; \text { subjective } \\
\text { hypersomnia }(\mathrm{n}=6)\end{array}$ & $\begin{array}{l}\text { Improvement on ESS: } \\
3.9 \text { points }\end{array}$ \\
\hline \multirow[t]{2}{*}{ Pemoline } & Ali et al., 2009 [19] & $67 \pm 37 \mathrm{mg}$ per day & IH (ICSD-2; $n=3)$ & $\begin{array}{l}100 \% \text { complete or } \\
\text { partial response }\end{array}$ \\
\hline & Ozaki et al., 2012 [31] & Unclear & $\begin{array}{l}\text { IH without long sleep time } \\
\quad(\text { ICSD- } 2 ; n=54)\end{array}$ & $\begin{array}{l}\text { Improvement on } \\
\text { ESS: } 3.7 \text { points }\end{array}$ \\
\hline Levothyroxine & Shinno et al., 2011 [32] & $25 / \mu \mathrm{g}$ per day & $\begin{array}{l}\text { IH with long sleep time } \\
\quad(\text { ICSD- } 2 ; n=9)\end{array}$ & $\begin{array}{l}\text { Improvement on } \\
\text { ESS: } 10.4 \\
\text { points; decrease in } \\
\text { daily sleep time: } \\
4.5 \mathrm{~h}\end{array}$ \\
\hline Melatonin & $\begin{array}{l}\text { Montplaisir et al., } 2001 \\
\text { [33] }\end{array}$ & $2 \mathrm{mg}$ & $\begin{array}{l}\text { Polysymptomatic } \\
\text { hypersomnia }(n=10)\end{array}$ & $50 \%$ responders \\
\hline $\begin{array}{l}\text { Transcranial direct current } \\
\text { stimulation }\end{array}$ & Galbiati et al., 2016 [15] & 12 stimulations & IH (ICSD-3; $n=8)$ & $\begin{array}{l}\text { Improvement on } \\
\text { ESS: } 5.8 \text { points }\end{array}$ \\
\hline
\end{tabular}

Doses are shown as mean $\pm \mathrm{SD}$, where applicable

CGI Clinical Global Impression, ESS Epworth Sleepiness Scale, ICSD International Classification of Sleep Disorders, IH idiopathic hypersomnia, ILC inappropriate line crossings, $N T 1$ narcolepsy type 1, NT2 narcolepsy type 2, $P S G$ polysomnography, $S D L P$ standard deviation of lateral position

subjective daytime sleepiness (ESS; NCT03597555), while another randomized controlled phase 3 trial assesses the same in 140 people with IH treated with JZP-258, a low-sodium variant of sodium oxybate (NCT03533114).

\section{Pitolisant}

Pitolisant is a compound that was found to be non-inferior to modafinil in people with narcolepsy, and experience in the offlabel treatment of IH has already accumulated. This adverse agonist of the histamine $\mathrm{H} 3$ autoreceptor stimulates histamine release in the cortex. A retrospective cohort study [25] in 65 people with treatment-refractory IH patients showed a responder rate of $35 \%$. However, $63 \%$ of all included individuals stopped using pitolisant, mostly due to lack of efficacy or adverse effects. Mean improvement of subjective daytime sleepiness on the ESS was 1.5 points.

\section{Mazindol}

Mazindol is a tricyclic non-amphetamine stimulant, originally marketed as an anorectic agent, that was shown to have an acceptable benefit/risk-ratio in a retrospective cohort of 37 people with IH refractory to modafinil, methylphenidate and sodium oxybate treatment [26]. However, mazindol was withdrawn from the market in 2010 , since a similar appetite-suppressing agent was found to have caused valvulopathies and pulmonary hypertension as a rare, but severe side effect [38].

\section{Solriamfetol}

With only a moderate effect of current stimulants in subpopulations of people with $\mathrm{IH}$, the emergence of a new effective stimulant for the treatment of narcolepsy, solriamfetol [39], holds promise for the treatment of excessive daytime sleepiness in $\mathrm{IH}$.

\section{GABA-A Receptor Antagonists}

A different category of pharmacological compound for the treatment of IH is based on a recent theory on its neurobiology. GABA signaling was found to be altered in people with IH: GABA-A receptors were potentiated by adding cerebrospinal fluid from these individuals [27]. However, this could not be replicated in another cohort of people with IH [40]. Based on this theory, several GABA-A receptor antagonists were assessed for their efficacy in IH.

The effect of flumazenil was described in 39 people with treatment-refractory IH in 3 studies [27-29]. Different treatment regimens led to a responder rate of $67 \%$. Adverse effects were reported in $52 \%$ of cases, of whom $20 \%$ decided to discontinue flumazenil treatment because of it.

Clarithromycin, another GABA-A receptor antagonist, investigated for the treatment of a mixture of narcolepsy, IH and other hypersomnolent conditions, showed a small decrease in subjective daytime sleepiness (ESS), but no vigilance improvement in a retrospective chart review and a randomized crossover trial $[6,30]$. Adverse effects were found in up to $95 \%$ of individuals. A new randomized controlled phase 2 trial in 92 people with narcolepsy type 2 and IH focusing on 
the effect of clarithromycin on subjective and objective daytime sleepiness is currently underway (NCT04026958). Two randomized controlled trials on the effect of a third GABA-A receptor antagonist, pentetrazole (BTD-001), on IH symptoms (IH symptom diary) and subjective daytime sleepiness (ESS) are also ongoing (NCT03542851 and NCT02512588, respectively).

\section{Other Compounds}

In a prospective open-label study, levothyroxine was reported to decrease total sleep time and subjective daytime sleepiness in 9 people with IH with long sleep time [32]. Pemoline [19, 31] and melatonin [33] have also been reported to be efficacious in people with treatment-refractory IH.

\section{Treatment Follow-up}

Many individuals with IH are treated sequentially with different types of medication due to lack of efficacy. Those with long sleep time seem to benefit less from pharmacological treatment. Additionally, prescribed medications are reported to have low effect on other symptoms of $\mathrm{IH}$, such as sleep inertia, reduced vigilance, and cognitive dysfunction during the day.

\section{Our Current Approach}

It is difficult to recommend any of the discussed drugs as first line treatment for IH. Since the efficacy of modafinil is the most consistently described and there is a lot of experience with this substance, it is reasonable to start with it as a first choice treatment. Methylphenidate and dexamphetamine are good alternatives. For the phenotype without an increased amount of sleep, it is of paramount importance first to exclude sleep deprivation as cause for the daytime complaints.

Sodium oxybate, pitolisant, and solriamfetol seem promising, but currently, there is not enough evidence to advise their use, particularly as first-line treatment.

We consider flumazenil and clarithromycin to be still experimental therapies. There is a clear need for more studies to confirm efficacy as well as safety.

\section{Summary}

The definition of IH has changed over time and the few treatment studies that have been performed are hampered by small sample sizes and the use of variable and often insufficiently validated outcome parameters. Non-pharmacological interventions and various compounds are, however, routinely used in sleep centers in the treatment of excessive daytime sleepiness in IH. Of these compounds, modafinil and methylphenidate are most commonly used. In the future, newer drugs such as sodium oxybate, pitolisant and solriamfetol might receive marketing authorization for use in $\mathrm{IH}$, depending on the results of the trials that are currently being performed. Hopefully, the pathophysiology of this disorder will be further elucidated, leading to more specific treatments.

\section{Human and Animal Rights Informed Consent}

This article does not contain any studies with human or animal subjects performed by any of the authors.

\section{Compliance with Ethical Standards}

Conflict of Interest Rolf Fronczek reports a travel grant and lecture fees from Bioprojet, outside the submitted work.

Mink Schinkelshoek reports a travel grant from Bioprojet, outside the submitted work.

Gert Jan Lammers reports consultancy for Jazz Pharmaceuticals, advisory board membership for Bioprojet on pitolisant, advisory board membership and grants from UCB, outside the submitted work.

Open Access This article is distributed under the terms of the Creative Commons Attribution 4.0 International License (http:// creativecommons.org/licenses/by/4.0/), which permits unrestricted use, distribution, and reproduction in any medium, provided you give appropriate credit to the original author(s) and the source, provide a link to the Creative Commons license, and indicate if changes were made.

\section{References}

Papers of particular interest, published recently, have been highlighted as:

- Of importance

•- Of major importance

1. ICSD. International classification of sleep disorders. 3rd ed. American Academy of Sleep Disorders: Darien, IL, USA; 2014.

2. Vernet C, Leu-Semenescu S, Buzare MA, Arnulf I. Subjective symptoms in idiopathic hypersomnia: beyond excessive sleepiness. J Sleep Res. 2010;19(4):525-34. https://doi.org/10.1111/j.13652869.2010.00824.x.

3. Lopez R, Doukkali A, Barateau L, Evangelista E, Chenini S, Jaussent I, et al. Test-retest reliability of the multiple sleep latency test in central disorders of hypersomnolence. Sleep. 2017;40(12). https://doi.org/10.1093/sleep/zsx164 This study highlights an important difficulty of research in idiopathic hypersomnia: it has become clear that the delineation from narcolepsy type 2 (NT2) (and sleep deprivation) is problematic.

4.• Trotti LM, Staab BA, Rye DB. Test-retest reliability of the multiple sleep latency test in narcolepsy without cataplexy and idiopathic hypersomnia. J Clin sleep med. 2013;9(8):789-95. https://doi.org/ $10.5664 / \mathrm{jcsm} .2922$ This study highlights for the first time an important difficulty of research in idiopathic hypersomnia: the test-retest unreliability of the multiple sleep latency test.

5.• Dauvilliers Y, Evangelista E, Barateau L, Lopez R, Chenini S, Delbos C, et al. Measurement of symptoms in idiopathic hypersomnia: the idiopathic hypersomnia severity scale. Neurology. 2019;92(15):e1754-e62. https://doi.org/10.1212/wnl. 
000000000007264 This study presents a scale that focuses on a broad range of symptoms of idiopathic hypersomnia and could thereby function as an important outcome measure in future research on idiopathic hypersomnia.

6. Trotti LM, Saini P, Bliwise DL, Freeman AA, Jenkins A, Rye DB. Clarithromycin in gamma-aminobutyric acid-related hypersomnolence: a randomized, crossover trial. Ann Neurol. 2015;78(3):45465. https://doi.org/10.1002/ana.24459.

7. Yaman M, Karakaya F, Aydin T, Mayda H, Guzel HI, Kayaalp D. Evaluation of the effect of modafinil on cognitive functions in patients with idiopathic hypersomnia with P300. Med Sci Monit. 2015;21:1850-5. https://doi.org/10.12659/msm.893448.

8. Philip P, Chaufton C, Taillard J, Capelli A, Coste O, Leger D, et al. Modafinil improves real driving performance in patients with hypersomnia: a randomized double-blind placebo-controlled crossover clinical trial. Sleep. 2014;37(3):483-7. https://doi.org/10. 5665/sleep.3480.

9. Trotti LM. Idiopathic hypersomnia. Sleep Med Clin. 2017;12(3): 331-44. https://doi.org/10.1016/j.jsmc.2017.03.009.

10. Billiard M, Sonka K. Idiopathic hypersomnia. Sleep Med Rev. 2016;29:23-33. https://doi.org/10.1016/j.smrv.2015.08.007.

11. Krahn LE, Hershner S, Loeding LD, Maski KP, Rifkin DI, Selim B, et al. Quality measures for the care of patients with narcolepsy. J Clin Sleep Med. 2015;11(3):335. https://doi.org/10.5664/jcsm. 4554.

12. Leu-Semenescu S, Quera-Salva MA, Dauvilliers Y, French consensus. Idiopathic hypersomnia: investigations and follow-up. Rev Neurol (Paris). 2017;173(1-2):32-7. https://doi.org/10.1016/j. neurol.2016.09.015.

13. Bassetti CLA, Adamantidis A, Burdakov D, Han F, Gay S, Kallweit U, et al. Narcolepsy - clinical spectrum, aetiopathophysiology, diagnosis and treatment. Nat Rev Neurol. 2019;15:519-39. https:// doi.org/10.1038/s41582-019-0226-9.

14. Neikrug AB, Crawford MR, Ong JC. Behavioral sleep medicine services for hypersomnia disorders: a survey study. Behav Sleep Med. 2017;15(2):158-71. https://doi.org/10.1080/15402002.2015. 1120201 .

15. Galbiati A, Abutalebi J, Iannaccone S, Borsa VM, Musteata S, Zucconi M, et al. The effects of transcranial direct current stimulation (TDCS) on idiopathic hypersomnia: a pilot study. Arch Ital Biol. 2016;154(1):1-5. https://doi.org/10.12871/00039829201611.

16. Mayer G, Benes H, Young P, Bitterlich M, Rodenbeck A. Modafinil in the treatment of idiopathic hypersomnia without long sleep timea randomized, double-blind, placebo-controlled study. J Sleep Res. 2015;24(1):74-81. https://doi.org/10.1111/jsr.12201.

17. Bastuji H, Jouvet M. Successful treatment of idiopathic hypersomnia and narcolepsy with modafinil. Prog NeuroPsychopharmacol Biol Psychiatry. 1988;12(5):695-700.

18. Anderson KN, Pilsworth S, Sharples LD, Smith IE, Shneerson JM. Idiopathic hypersomnia: a study of 77 cases. Sleep. 2007;30(10): 1274-81. https://doi.org/10.1093/sleep/30.10.1274.

19. Ali M, Auger RR, Slocumb NL, Morgenthaler TI. Idiopathic hypersomnia: clinical features and response to treatment. J Clin Sleep Med. 2009;5(6):562-8.

20. Lavault S, Dauvilliers Y, Drouot X, Leu-Semenescu S, Golmard JL, Lecendreux M, et al. Benefit and risk of modafinil in idiopathic hypersomnia vs. narcolepsy with cataplexy. Sleep Med. 2011;12(6):550-6. https://doi.org/10.1016/j.sleep.2011.03.010.

21. Janackova S, Motte J, Bakchine S, Sforza E. Idiopathic hypersomnia: a report of three adolescent-onset cases in a twogeneration family. J Child Neurol. 2011;26(4):522-5. https://doi. org/10.1177/0883073810384865.

22. Bassetti C, Aldrich MS. Idiopathic hypersomnia. A series of 42 patients. Brain. 1997;120(Pt 8):1423-35. https://doi.org/10.1093/ brain/120.8.1423.
23. Thakrar C, Patel K, D'Ancona G, Kent BD, Nesbitt A, Selsick H, et al. Effectiveness and side-effect profile of stimulant therapy as monotherapy and in combination in the central hypersomnias in clinical practice. J Sleep Res. 2018;27(4):e12627. https://doi.org/ $10.1111 /$ jsr. 12627.

24. Leu-Semenescu S, Louis P, Arnulf I. Benefits and risk of sodium oxybate in idiopathic hypersomnia versus narcolepsy type 1: a chart review. Sleep Med. 2016;17:38-44. https://doi.org/10.1016/j.sleep. 2015.10.005 This is the first study to describe the efficacy of sodium oxybate in a idiopathic hypersomnia population. Since the results of this retrospective study were promising, this study paved the way for a couple of ongoing trials on the efficacy of sodium oxybate in idiopathic hypersomnia.

25. Leu-Semenescu S, Nittur N, Golmard JL, Arnulf I. Effects of pitolisant, a histamine H3 inverse agonist, in drug-resistant idiopathic and symptomatic hypersomnia: a chart review. Sleep Med. 2014;15(6):681-7. https://doi.org/10.1016/j.sleep.2014.01.021.

26. Nittur N, Konofal E, Dauvilliers Y, Franco P, Leu-Semenescu S, Cock VC, et al. Mazindol in narcolepsy and idiopathic and symptomatic hypersomnia refractory to stimulants: a long-term chart review. Sleep Med. 2013;14(1):30-6. https://doi.org/10.1016/j. sleep.2012.07.008.

27. Rye DB, Bliwise DL, Parker K, Trotti LM, Saini P, Fairley J, et al. Modulation of vigilance in the primary hypersomnias by endogenous enhancement of GABAA receptors. Sci Transl Med. 2012;4(161):161-51. https://doi.org/10.1126/scitranslmed. 3004685.

28. Kelty E, Martyn V, O'Neil G, Hulse G. Use of subcutaneous flumazenil preparations for the treatment of idiopathic hypersomnia: a case report. J Psychopharmacol. 2014;28(7):7036. https://doi.org/10.1177/0269881114523865.

29. Trotti LM, Saini P, Koola C, LaBarbera V, Bliwise DL, Rye DB. Flumazenil for the treatment of refractory Hypersomnolence: clinical experience with 153 patients. J Clin Sleep Med. 2016;12(10): 1389-94. https://doi.org/10.5664/jcsm.6196.

30. Trotti LM, Saini P, Freeman AA, Bliwise DL, Garcia PS, Jenkins A, et al. Improvement in daytime sleepiness with clarithromycin in patients with GABA-related hypersomnia: clinical experience. J Psychopharmacol. 2014;28(7):697-702. https://doi.org/10.1177/ 0269881113515062.

31. Ozaki A, Inoue Y, Hayashida K, Nakajima T, Honda M, Usui A, et al. Quality of life in patients with narcolepsy with cataplexy, narcolepsy without cataplexy, and idiopathic hypersomnia without long sleep time: comparison between patients on psychostimulants, drug-naive patients and the general Japanese population. Sleep Med. 2012;13(2):200-6. https://doi.org/10.1016/j.sleep.2011.07. 014.

32. Shinno H, Ishikawa I, Yamanaka M, Usui A, Danjo S, Inami Y, et al. Effect of levothyroxine on prolonged nocturnal sleep time and excessive daytime somnolence in patients with idiopathic hypersomnia. Sleep Med. 2011;12(6):578-83. https://doi.org/10. 1016/j.sleep.2011.02.004.

33. Montplaisir J, Fantini L. Idiopathic hypersomnia: a diagnostic dilemma. A commentary of "idiopathic hypersomnia" (M. Billiard and Y. Dauvilliers). Sleep Med Rev. 2001;5(5):361-2. https://doi. org/10.1053/smrv.2001.0216.

34. Billiard M. Idiopathic hypersomnia. Neurol Clin. 1996;14(3):57382.

35. Vodovar D, Duchene A, Wimberley C, Leroy C, Pottier G, Dauvilliers $\mathrm{Y}$, et al. Cortico-amygdala-striatal activation by modafinil/flecainide combination. Int J Neuropsychopharmacol. 2018;21(7):687-96. https://doi.org/10.1093/ijnp/pyy027.

36. Duchene A, Perier M, Zhao Y, Liu X, Thomasson J, Chauveau F, et al. Impact of astroglial connexins on modafinil pharmacological properties. Sleep. 2016;39(6):1283-92. https://doi.org/10.5665/ sleep.5854. 
37. Sauvet F, Erblang M, Gomez-Merino D, Rabat A, Guillard M, Dubourdieu H, et al. Efficacy of THN102 (a combination of modafinil and flecainide) on vigilance and cognition during 40hour total sleep deprivation in healthy subjects: glial connexins as a therapeutic target. Br J Clin Pharmacol. 2019. https://doi.org/10. 1111/bcp.14098 This study describes an addition to the first choice treatment for idiopathic hypersomnia that could possibly increase the efficacy of this compound and could potentially prove to be a step forward in treating people with idiopathic hypersomnia.

38. Ryan DH, Bray GA, Helmcke F, Sander G, Volaufova J, Greenway $\mathrm{F}$, et al. Serial echocardiographic and clinical evaluation of valvular regurgitation before, during, and after treatment with fenfluramine or dexfenfluramine and mazindol or phentermine. Obes Res. 1999;7(4):313-22.

39. Thorpy MJ, Shapiro C, Mayer G, Corser BC, Emsellem H, Plazzi $\mathrm{G}$, et al. A randomized study of solriamfetol for excessive sleepiness in narcolepsy. Ann Neurol. 2019;85(3):359-70. https://doi. org/10.1002/ana.25423.

40. Dauvilliers Y, Evangelista E, Lopez R, Barateau L, Jaussent I, Cens $\mathrm{T}$, et al. Absence of gamma-aminobutyric acid-a receptor potentiation in central hypersomnolence disorders. Ann Neurol. 2016;80(2):259-68. https://doi.org/10.1002/ana.24710.

Publisher's Note Springer Nature remains neutral with regard to jurisdictional claims in published maps and institutional affiliations. 